\title{
Frequência de neoplasmas em cães diagnosticados por exame citológico: estudo retrospectivo em um hospital-escola
}

\section{Frequency of tumors in dogs based on cytological diagnosis: a retrospective study in a veterinary teaching hospital}

\author{
Victor José Vieira Rossetto ${ }^{1}$; Kleber Moreno ${ }^{2}$; Claudia Bosselli Grotti ${ }^{3}$; Antonio \\ Carlos Faria dos Reis ${ }^{4}$; Ana Paula Frederico Rodrigues Loureiro Bracarense ${ }^{5 *}$
}

\section{Resumo}

\begin{abstract}
O exame citológico é um importante método de diagnóstico de neoplasias em animais de companhia e pode ser realizado em diversas situações clínicas. O objetivo do presente estudo foi determinar a prevalência dos neoplasmas diagnosticados pelo exame citológico em cães atendidos na região de Londrina e avaliar aspectos epidemiológicos relacionados à idade, raça, sexo, comportamento e localização anatômica. Foram avaliados 3788 registros, provenientes da rotina do Laboratório de Anatomia Patológica da Universidade Estadual de Londrina, durante o período de janeiro de 1996 a dezembro de 2006. Dentre estes, 1019 registros foram diagnosticados como neoplasmas. Os neoplasmas de células redondas representaram $44 \%$ dos diagnósticos, seguidos pelos neoplasmas epiteliais e mesenquimais com 36,7\% e $16 \%$, respectivamente. Os neoplasmas indiferenciados totalizaram 3,3\% dos diagnósticos citológicos. Em relação ao comportamento biológico, o comportamento maligno foi mais freqüente nos neoplasmas epiteliais do que nos mesenquimais. Dentre os tumores de células redondas, o mastocitoma, o tumor venéreo transmissível e o linfoma foram os mais significantemente representados. Os cães com raça definida foram os mais acometidos e dentre esses, as raças boxer, poodle e pastor alemão foram as de maior prevalência. A média de idade foi de 7,94 $\pm 3,55$ anos. Não foi observada diferença estatística significativa em relação ao sexo. O períneo foi a localização anatômica preferencial nos neoplasmas epiteliais benignos e tumor venéreo transmissível, enquanto que os tumores mesenquimais benignos localizavam-se freqüentemente na região torácica. Neoplasmas epiteliais e mesenquimais malignos, melanoma e histiocitoma localizavam-se principalmente na cabeça. O mastocitoma apresentou-se mais comumentemente no tronco e membros. Já a manifestação clínica mais freqüente observada no linfoma foi a linfoadenomegalia.
\end{abstract}

Palavras chave: Oncologia, citologia, neoplasmas, epidemiologia, cães

\begin{abstract}
1 Graduando em Medicina Veterinária da Universidade Estadual de Londrina, PR.

Programa de Pós-Graduação em Ciência Animal/UEL.

Médica Veterinária, depto. Med. Vet. Preventiva/UEL.

4 Professor Adjunto, depto. Med. Vet. Preventiva/UEL.

5 Professor Associado, depto. Med. Vet. Preventiva/UEL. E-mail: anapaula@uel.br

Autor para correspondência
\end{abstract}

Cytological examination is considered a very important method to diagnose neoplasms in pets and can be performed in many clinical situations. The aim of this study was to determine the prevalence of neoplasms diagnosed by cytological examination in dogs from the region of Londrina, and to evaluate epidemiological aspects as age, breed, sex predisposition, biological behaviour and anatomical localization. The data were obtained from the Animal Pathology Laboratory of Universidade Estadual de Londrina. 3378 cases of cytological examinations from the routine service of the laboratory were 
evaluated, from January 1996 to December 2006. From these, 1019 cases were diagnosed as neoplasms. Round cell tumors represented $44 \%$ of the diagnosis, followed by epithelial and mesenchymal neoplasms with $36.7 \%$ and $16 \%$, respectively. Undifferentiated neoplasms totalized $3.3 \%$ of the cytological diagnosis. Malignant behaviour were more frequent in epithelial than mesenchymal neoplasms. Mast cell tumor, transmissible venereal tumor and lymphoma were the neoplasms more frequently diagnosed within round cell tumors. Pure breeds were more prevalent than mongrel dogs. Boxers, poodles and German shepherds were the most affected by neoplasms. The average age was $7.94 \pm 3.55$ years. There was no sex predisposition. Perineum was the most affected site in benign epithelial neoplasms and transmissible venereal tumors, whereas benign mesenchymal neoplasms were often located in thorax. Malignant epithelial and mesenchymal neoplasms, melanoma and histiocytoma were located mainly in the head. Mast cell tumors were observed mainly in trunk and limbs. The most common clinical sign in lymphoma was lymphadenomegaly.

Key words: Oncology, cytology, neoplasm, epidemiology, dogs

\section{Introdução}

Atualmente, a oncologia é considerada uma área de grande importância na Medicina Veterinária, prova disso é a grande quantidade de livros, artigos científicos e eventos realizados sobre este tema na última década (SOUZA et al., 2006). Estima-se que os neoplasmas estejam relacionados com a primeira causa de morte de animais de companhia. Em estudos recentes, mostrou-se que $45 \%$ dos cães com 10 anos ou mais, morreram devido a neoplasmas e suas complicações (WITHROW, 2007).

A alta prevalência de tumores decorre de diversos fatores, como o aumento na longevidade dos animais de companhia. Esse incremento na estimativa de vida ocorre em razão das vacinações, fornecimento de rações melhor balanceadas, protocolos terapêuticos mais específicos e eficazes e outras alterações de manejo por parte dos proprietários (MARIA; SOBRAL; DALECK, 1998; WITHROW, 2007). Além disso, os proprietários estão cada vez mais atentos aos seus animais e procuram assistência veterinária para diagnóstico precoce, o que contribui grandemente no aumento da estimativa de vida (REPPAS; CANFIELD, 1995).

A citologia foi introduzida recentemente na rotina veterinária brasileira, apresentando maior destaque a partir da década de 90 (GUEDES et al., 2000). O exame citológico destina-se, entre outras aplicações, ao diagnóstico precoce de neoplasmas e consiste no estudo morfológico de células livres ou isoladas de múltiplos tecidos, órgãos e fluidos e possui grande valor diagnóstico, pois as alterações das células naturalmente descamadas ou retiradas artificialmente, podem representar modificações estruturais e celulares do tecido subjacente (BRACARENSE; REIS, 1997; RASKIN, 2003).

O exame citológico é de grande importância dentre os métodos de diagnóstico de neoplasmas em animais de companhia, pois é relativamente não invasivo, seguro, simples, de baixo custo, apresenta rapidez na determinação do resultado e pode ser realizado em diversas situações clínicas, tornandose uma extensão do exame físico (LEVER; TROTT; WEBB, 1985; WELLMAN, 1996;).

Adicionalmente, sabe-se que a citologia apresenta alta correlação com a histologia, sendo encontrados valores entre $83,3 \%$ a $92 \%$ (BRACARENSE; REIS, 1997; BUSSADORI et al., 2004; GUEDES et al., 2000; MAGALHÃES et al., 2001; MÉNARD; FONTAINE; MORIN, 1986; MILLS; GRIFFITHS, 1984). Segundo Guedes et al. (2000), este índice aumenta para $95 \%$ quando se considera apenas neoplasmas de células redondas, pois essas possuem características que são bem definidas pela citologia.

Além da determinação da origem celular e diagnóstico de diversos tumores, a citologia é também utilizada na diferenciação de processos inflamatórios ou hiperplásicos, no estabelecimento do prognóstico,na identificação de metástase tumoral 
e no monitoramento da involução de neoplasmas, seguida de terapia antineoplásica e da recidiva local (MAGALHÃES et al., 2001; WELLMAN, 1996).

A interpretação do exame citológico deve ser realizada correlacionando-se as características citomorfológicas com dados obtidos a partir da resenha, anamnese, exame físico, aspectos macroscópicos da lesão, localização anatômica, entre outras informações. Do mesmo modo, a experiência do patologista e o conhecimento das características celulares normais são fundamentais na determinação do diagnóstico citológico (LARKIN, 1994; MÉNARD; FONTAINE; MORIN, 1986; WELLMAN, 1996).

O objetivo do presente trabalho foi analisar os aspectos epidemiológicos e determinar a prevalência por meio de estudo retrospectivo do diagnóstico citológico de neoplasmas que acometem cães atendidos no Hospital Veterinário da Universidade Estadual de Londrina (UEL).

\section{Material e Métodos}

Foram avaliados 3788 registros de exames citológicos provenientes da rotina do Laboratório de Patologia Animal/UEL, durante o período de janeiro de 1996 a dezembro de 2006. Os registros foram obtidos a partir de animais atendidos pelo Hospital Veterinário/UEL ou encaminhados por clínicas particulares da região de Londrina, Paraná. Foram considerados neste estudo, apenas os diagnósticos citológicos relacionados a neoplasmas, tanto de origem cutânea como de órgãos internos. Não foram incluídos, contudo, os tumores originários da glândula mamária.

As lesões foram classificadas de acordo com as características citomorfológicas gerais em epiteliais, mesenquimais, de células redondas e indiferenciadas. Os neoplasmas epiteliais e mesenquimais foram subclassificados em benignos e malignos, com base nos critérios propostos por Morrison e Denicola (1993). Os tumores de células redondas foram classificados em tumor venéreo transmissível (TVT), linfoma, mastocitoma, histiocitoma e plasmocitoma. Os melanomas foram classificados como neoplasmas mesenquimais como proposto por Raskin (2003) e Tyler et al. (1999).

Foi estabelecida a prevalência quanto à faixa etária, sexo e raça, bem como da classificação acima em relação ao total de registros de diagnósticos citológicos de neoplasmas. Avaliou-se também a localização anatômica de acordo com os critérios propostos por Goldschimdt e Shofer (1992), assim como as raças com a classificação e subclassificação dos tumores. Na análise epidemiológica, os animais foram classificados em relação ao sexo como macho e fêmea, independente de serem castrados ou não.

Para a análise estatística, utilizou-se o teste de $\chi^{2}$ utilizando o nível de significância de $5 \%(\mathrm{P}<0,05)$. As análises foram realizadas com o auxilio do programa EPI-INFO 6.04 (DEAN et al., 1994).

\section{Resultados}

Dos 3788 exames citológicos, 26,9\% (1019) eram referentes a neoplasmas acometendo cães. Os tumores de células redondas constituíram 44,85\% (457/1019) do total de neoplasmas, seguidos pelos epiteliais com 35,42\% (361/1019), mesenquimais com 16,39\% (167/1019) e neoplasmas cuja diferenciação não foi possível apenas por meio do exame citológico que totalizaram $3,34 \%$ do total (34/1019). Entre os tumores de células redondas, mastocitoma, TVT e linfoma foram os mais freqüentemente representados (Tabela 1). 
Tabela 1. Classificação citológica de neoplasmas acometendo cães atendidos no Hospital Veterinário/UEL no período de 1996-2006.

\begin{tabular}{ccc}
\hline Neoplasma & Subclassificação & $\mathbf{n}(\mathbf{\%})$ \\
\hline \multirow{3}{*}{ Epitelial } & Benigna & $87(8,54)$ \\
& Maligna & $214(21,00)$ \\
& M. I. & $60(5,88)$ \\
\hline \multirow{2}{*}{ Mesenquimal } & Benigna & $44(4,32)$ \\
& Maligna & $52(5,10)$ \\
& Melanoma & $27(2,65)$ \\
& M. I. & $71(6,98)$ \\
\hline Célula Redonda & TVT & $121(11,87)$ \\
& Mastocitoma & $123(12,07)$ \\
& Histiocitoma & $22(2,16)$ \\
& Linfoma & $108(10,60)$ \\
\hline Indiferenciada & M. I. & $56(5,49)$ \\
\hline Total & & $34(3,34)$ \\
\hline
\end{tabular}

M. I. = Malignidade indeterminada.

A freqüência dos neoplasmas ao longo do período avaliado está disposta na figura 1. A ocorrência de tumores mesenquimais foi constante $(15,19 \pm 6,4$ casos por ano). Os tumores epiteliais e de células redondas apresentaram no período compreendido entre 1996 a 2002, média de 38,85 e 36 casos/ anos, respectivamente. A partir de 2003, entretanto, observou-se uma menor ocorrência do tipo epitelial (27,5 casos/ano), acompanhada por um aumento na freqüência dos tumores de células redondas (45 casos/ano). Constatou-se ainda, incremento no número de amostras enviadas para diagnóstico citológico entre 1996 a 2006 na ordem de $88 \%$.

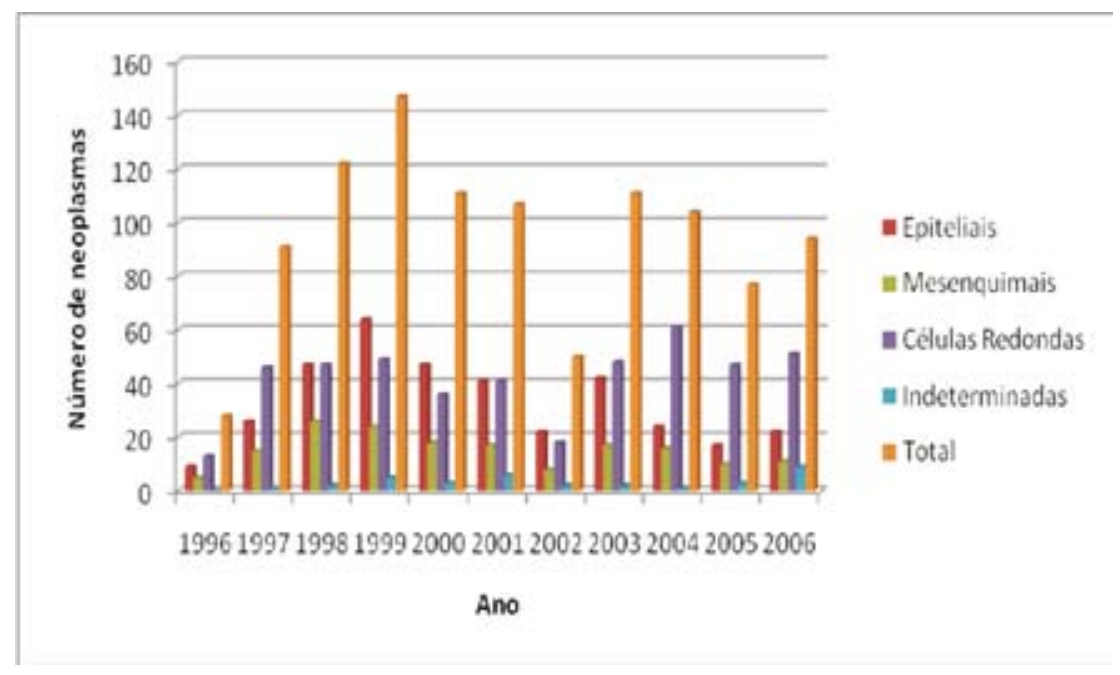

Figura 1. Frequência de neoplasmas em cães diagnosticados por exame citológico no período de 1996-2006 no Hospital Veterinário/UEL. 
A freqüência dos diferentes tipos de tumores em relação a sua origem e comportamento está representada na tabela 1 . O comportamento maligno foi mais freqüente nos tumores epiteliais $(60,73 \%)$ do que nos mesenquimais $(31,14 \%)$. Neste grupo, em $42,52 \%$ dos casos, a malignidade não pode ser determinada pelo exame citológico.

As principais localizações anatômicas estão apresentadas na tabela 2. Entre os neoplasmas epiteliais benignos, a localização mais comum foi a região perineal (47,13\%), englobando áreas como o períneo, ânus, testículos, vulva e vagina, enquanto que os de comportamento maligno localizaramse preferencialmente em cabeça e região cervical $(20,08 \%)$. Dentre os tumores epiteliais, os diagnósticos sugestivos de adenomas perianais foram freqüentes.

Tabela 2. Localizações anatômicas de neoplasmas acometendo cães atendidos no Hospital Veterinário/UEL no período de 1996-2006.

\begin{tabular}{lccccccccc}
\hline & \multicolumn{2}{c}{ Epithelial } & \multicolumn{3}{c}{ Mesenquimal } & \multicolumn{3}{c}{ Tumor de células redondas } \\
\hline Localizações & Benig & Malig & Benig & Malig & Mel. & Linf. & Hist. & Mast. & TVT \\
\hline Membro posterior & 7 & 23 & 6 & 9 & 6 & 0 & 3 & 31 & 0 \\
Membro anterior & 7 & 19 & 5 & 10 & 2 & 3 & 4 & 12 & 0 \\
Região abdominal & 0 & 26 & 4 & 0 & 0 & 3 & 3 & 10 & 29 \\
Cabeça/ R. cervical & 13 & 48 & 4 & 12 & 7 & 9 & 7 & 10 & 26 \\
Cavidade oral & 3 & 18 & 4 & 5 & 5 & 0 & 0 & 2 & 5 \\
Região torácica & 3 & 15 & 10 & 5 & 1 & 5 & 1 & 10 & 1 \\
Região perineal & 41 & 20 & 4 & 0 & 1 & 0 & 0 & 19 & 49 \\
Dorso & 4 & 8 & 0 & 0 & 0 & 0 & 0 & 5 & 2 \\
Outras & 5 & 30 & 4 & 8 & 2 & 15 & 1 & 5 & 4 \\
Não constam & 4 & 20 & 3 & 6 & 4 & 25 & 3 & 17 & 15 \\
\hline Total & $\mathbf{8 7}$ & $\mathbf{2 3 9}$ & $\mathbf{4 4}$ & $\mathbf{5 5}$ & $\mathbf{2 8}$ & $\mathbf{1 1 9}$ & $\mathbf{2 2}$ & $\mathbf{1 3 4}$ & $\mathbf{1 3 6}$ \\
\hline
\end{tabular}

Benig $=$ benigna; Malig $=$ maligna; Mel. $=$ melanoma; Linf. $=$ linfoma; Hist. $=$ histiocitoma; Mast. = mastocitoma; $\mathrm{TVT}=$ tumor venéreo transmissível; R.cervical = região cervical.

Os neoplasmas mesenquimais benignos localizaram-se mais comumente na região torácica $(22,73 \%)$ e os malignos na cabeça e região cervical $(21,82 \%)$, seguida de membros $(34,54 \%)$. Dentre estes, os osteossarcomas foram freqüentemente diagnosticados. $\mathrm{O}$ melanoma acometeu principalmente a cabeça e região cervical $(25 \%)$, membros posteriores $(21,43 \%)$ e cavidade oral $(17,86 \%)$.

O TVT localizou-se preferencialmente em região perineal $(36,03 \%)$, particularmente a genitália externa. $\mathrm{O}$ histiocitoma foi observado mais comumente na cabeça e região cervical $(31,82 \%)$. $\mathrm{O}$ mastocitoma localizou-se preferencialmente em membro posterior $(23,13 \%)$. Além das localizações anatômicas apresentadas na tabela 2, a glândula mamária foi acometida pelo mastocitoma em $9,70 \%$ (13/134) dos casos. A manifestação mais comumente encontrada nos casos de linfoma foi a linfoadenomegalia (49/119) generalizada ou em um único linfonodo, seguida pela forma cutânea difusa $(10 / 119)$ e pelas localizações apresentadas na tabela 2.

A média de idade dos cães acometidos foi de 7,94 $\pm 3,55$ anos. Os resultados referentes à idade associados à classificação citológica e ao comportamento dos tumores estão dispostos na tabela 3 . 
Tabela 3. Idade média e desvio padrão de cães com tumores cutâneos atendidos no Hospital Veterinário/UEL.

\begin{tabular}{cllc}
\hline Neoplasma & \multicolumn{1}{c}{ Idade média } & \multicolumn{1}{c}{ Classificação } & Idade média \\
\hline \multirow{2}{*}{ Epitelial } & \multirow{2}{*}{8,64 anos $\pm 3,70$} & Benigna & $9,12 \pm 3,47$ \\
& & Maligna & $8,58 \pm 3,73$ \\
\cline { 3 - 3 } Mesenquimal & \multirow{2}{*}{7,80 anos $\pm 3,56$} & Benigna & $8,45 \pm 3,53$ \\
& & Maligna & $7,49 \pm 3,46$ \\
\cline { 3 - 3 } Células redondas & Melanoma & $8,34 \pm 2,95$ \\
\cline { 3 - 4 } & \multirow{2}{*}{7,37 anos $\pm 3,37$} & Linfoma & $6,62 \pm 2,69$ \\
& & Histicitoma & $3,33 \pm 3,17$ \\
& & Mastocitoma & $8,45 \pm 3,16$ \\
& & TVT & $5,09 \pm 2,84$ \\
\hline
\end{tabular}

Quanto à distribuição pelo sexo, dos cães acometidos por neoplasmas epiteliais, 193 eram machos e 157 fêmeas; mesenquimais, 81 machos e 85 fêmeas e tumores de células redondas, 214 machos e 223 fêmeas. Não foi observada diferença estatística significativa em relação ao sexo.

A distribuição quanto às raças caninas acometidas pelos diferentes tipos de neoplasmas está representada na tabela 4. Os dados apresentados revelam que cães com raça definida foram mais acometidos $(70,74 \%)$ do que os sem raça definida $(29,26 \%)$. Dentre as raças definidas, o pastor alemão foi o mais acometido pelos neoplasmas em geral com 11,96\% (81/677), seguido por cães das raças boxer com 11,67\% (79/677), poodle com $10,63 \%$ (72/677) e fila brasileiro com 7,09\% (48/677).

Tabela 4. Frequência de cães sem raça definida (SRD) e de raças caninas acometidas por neoplasmas no período de 1996-2006 no Hospital Veterinário/UEL.

\begin{tabular}{lcccc}
\hline \multicolumn{1}{c}{ Raças } & Epiteliais & Mesenquimais & Células Redondas & Total \\
\hline Akita & 1 & 2 & 3 & 6 \\
Boxer & 21 & 10 & 48 & 79 \\
Cocker & 20 & 2 & 22 & 44 \\
Doberman & 12 & 8 & 5 & 25 \\
Dogue Alemão & 6 & 9 & 11 & 26 \\
Fila Brasileiro & 13 & 12 & 23 & 48 \\
Fox Paulistinha & 7 & 1 & 3 & 11 \\
Husky Siberiano & 3 & 1 & 5 & 9 \\
Pastor Alemão & 38 & 14 & 26 & 81 \\
Pinscher & 5 & 0 & 19 & 24 \\
Poodle & 48 & 13 & 11 & 72 \\
Rottweiler & 8 & 17 & 11 & 36 \\
Sheep Dog & 4 & 0 & 2 & 6 \\
Teckel & 8 & 6 & 24 & 38 \\
Outras raças & 20 & 9 & 20 & 49 \\
SRD & 134 & 60 & 196 & 280 \\
\hline Total & $\mathbf{3 6 1}$ & $\mathbf{1 6 7}$ & $\mathbf{4 2 9}$ & $\mathbf{9 5 7}$ \\
\hline
\end{tabular}


Dentre os cães de raça acometidos por tumores epiteliais (227), as maiores freqüências ocorreram em poodle $(21,15 \%)$, pastor alemão $(16,74 \%)$, boxer $(9,25 \%)$ e cocker $(8,81 \%)$. Os cães boxer apresentaram maior prevalência de tumores de células redondas $(21,15 \%)$, acompanhados por pastor alemão (11,45\%), teckel $(10,57 \%)$, fila brasileiro $(10,13 \%)$ e cocker $(9,69 \%)$. A raça rottweiler foi a mais acometida por neoplasmas mesenquimais $(7,49 \%)$.

\section{Discussão}

O incremento no número de exames citológicos enviados para diagnóstico ao longo dos anos reflete o interesse que os clínicos veterinários têm demonstrado por um tipo de exame que permite um diagnóstico rápido, de baixo custo e acurado. $\mathrm{O}$ exame citológico tem sido considerado no Hospital Veterinário da Universidade Estadual de Londrina como um exame complementar inicial que facilita o planejamento cirúrgico e/ou o estabelecimento de protocolos terapêuticos. É importante ressaltar que este método não exclui a necessidade do envio de amostras para o exame histopatológico.

A prevalência de neoplasmas em cães, descrita no presente estudo, foi maior que a observada por Bellei et al. (2006), que ao avaliar tumores cutâneos por meio do exame histopatológico, diagnosticaram neoplasmas em 9,70\% (1065/10935). Pires, Travassos e Pires (2003), também avaliando lesões pelo exame histopatológico, observaram 45,60\% (1790/3922) de diagnósticos de neoplasmas acometendo cães. Estes autores, no entanto, incluíram na amostra os tumores mamários, o que justifica a maior ocorrência de neoplasmas.

Quanto à frequência das lesões ao longo do período avaliado, a razão para o aumento e a diminuição da quantidade de animais acometidos, respectivamente, por tumores de células redondas e epiteliais, a partir do ano de 2003, ainda permanece incerta.
Em relação à prevalência dos neoplasmas de acordo com as características citomorfológicas, resultados semelhantes foram encontrados por Bracarense e Reis (1997), avaliando 600 amostras por meio dos exames citológico e histopatológico. Os tumores de células redondas, segundo estes autores, representaram 37,64\% dos diagnósticos de neoplasmas, seguidos pelos epiteliais e mesenquimais, com respectivamente $26,24 \%$ e 7,31\%. Ménard, Fontaine e Morin (1986), em estudo que avaliou 102 casos por meio dos diagnósticos citológico e histopatológico, entretanto, encontraram uma maior representação dos neoplasmas epiteliais $(32,35 \%)$, seguidos pelos mesenquimais (31,37\%) e de células redondas (31,28\%). A maior representação dos neoplasmas de células redondas deve-se tanto à maior prevalência desse tipo de tumor na população avaliada, quanto à facilidade de esfoliação e concordância entre o exame citológico e histopatológico (DUNCAN; PRASSE, 1979; GUEDESetal.,2000;WELLMAN,1996).Éprovável ainda que os tumores de células redondas apresentem uma maior freqüência no Brasil, devido ao elevado número de casos de tumor venéreo transmissível, o que não ocorre nos países do hemisfério norte em que a castração precoce e o baixo número de cães errantes previne a disseminação deste tumor (Barbara Kitchell, comunicação pessoal). OrtegaPacheco et al. (2007) verificaram que em condições tropicais o TVT representou $15,3 \%$ das patologias reprodutivas em cadelas. A menor representação do tipo mesenquimal, provavelmente, deve-se ao fato destes tumores possuírem pobre celularidade e presença de grande quantidade de matriz extracelular. Tais características tornam difícil a determinação do diagnóstico por meio da citologia e o exame histopatológico é fundamental para a visualização da arquitetura tecidual (MÉNARD; FONTAINE; MORIN, 1986; WELLMAN, 1996).

Em relação ao comportamento biológico constatou-se maior prevalência de tumores malignos. Este resultado é similar relatado em outros estudos (BRACARENSE; REIS, 1997; SOUZA et al., 
2006). Uma das hipóteses para este predomínio é a demora por parte do proprietário em conduzir o animal para avaliação clínica e estabelecimento de diagnóstico precoce, propiciando uma evolução longa e aumento da possibilidade de transformação maligna.

No presente estudo não foram verificados casos de plasmocitoma, uma vez que o diagnóstico citológico dessa neoplasia torna-se complexo pela grande diversidade de características citomorfológicas que as células podem apresentar, podendo ser claramente plasmocitóides em algumas situações e em outras, pouco diferenciadas de uma população de células redondas (TYLER et al., 1999).

A grande ocorrência de tumores epiteliais benignos acometendo a região perineal deve-se, provavelmente, à alta prevalência de adenomas da glândula perianal. Esta neoplasia compreende cerca de $80 \%$ dos tumores localizados na região perineal (WITHROW, 2007). Segundo Pires, Travassos e Pires (2003), estes foram os neoplasmas epiteliais mais freqüentes $(29,8 \%)$ quando comparados aos demais tipos. Dobson et al. (2002) verificaram que a região perineal foi a segunda mais comumente acometida por todos os tumores da pele e de tecidos moles.

A localização anatômica preferencial dos neoplasmas epiteliais e mesenquimais malignos na cabeça e região cervical deve-se, provavelmente, a grande prevalência dos diferentes tipos decarcinomas acometendo esta região, particularmente o carcinoma de células escamosas, e aos tumores de origem vascular, como o hemangiossarcoma. Uma possível justificativa para este fato seria que a cabeça e a região cervical são mais expostas, comparadas a outras áreas corporais, aos diversos agentes carcinogênicos, como a radiação ultravioleta. Carcinomas de células escamosas e hemangiossarcomas cutâneos são mais freqüentemente encontrados em cães com pobre pigmentação da pele e pêlos curtos e podem ser associados à exposição à radiação ultravioleta (MACEWEN, 2001; VAIL; WITHROW, 2007).
Segundo Souza et al. (2006), o carcinoma de células escamosas foi a segunda neoplasia cutânea mais comumente observada e a cabeça, a localização anatômica mais acometida por neoplasmas cutâneos.

O melanoma localizou-se preferencialmente na cabeça e região cervical, provavelmente por essas regiões estarem mais expostas à radiação solar $\mathrm{e}$ conseqüentemente ao seu efeito. A relação existente entre a exposição solar e o desenvolvimento de melanomas cutâneos já é conhecida na medicina humana, entretanto a etiologia em cães e gatos ainda permanece incerta (GALLAGHER; LEE, 2006; HARRISON; MACLENNAN; BUETTNER, 2008; PEHARDA et al., 2007; SITUM et al., 2007; VAIL; WITHROW, 2007). De acordo com a literatura, os melanomas dérmicos têm um curso benigno e representam 9 a $20 \%$ dos tumores cutâneos, enquanto que na cavidade oral e dígitos, o melanoma é o neoplasma maligno de maior ocorrência (KOENIG et al., 2001). Resultados semelhantes foram observados neste estudo, em que membros posteriores e boca foram sítios anatômicos freqüentemente afetados por melanomas.

O TVT localizou-se preferencialmente na região perineal, particularmente na genitália externa, assim como observado por outros autores, embora também tenha sido verificada a ocorrência extragenital (DE NARDI et al., 2002; PIRES; TRAVASSOS; PIRES, 2003). Quanto ao histiocitoma, resultados diferentes foram observados por Dobson et al. (2002) ao avaliarem neoplasmas cutâneos. Segundo esses autores, o histiocitoma foi o tumor cutâneo mais freqüente e a cabeça, ao contrário do observado neste estudo, a quinta localização anatômica mais acometida. As localizações anatômicas do mastocitoma foram mais freqüentes nos membros posteriores e região perineal, diferindo do relatado por Rocha et. al. (2004) e Thamm e Vail (2001) que observaram este tumor principalmente no tronco (50\%). Quanto ao linfoma, a linfoadenomegalia generalizada também foi a manifestação mais comumente observada por Cohen et al. (1974) e 
Moreno e Bracarense (2007). A linfoadenomegalia consiste em um dos achados clínicos mais sugestivos e ocorre em $80 \%$ dos cães com linfoma multicêntrico (VAIL; MACEWEN; YOUNG, 2001).

$\mathrm{O}$ número total de neoplasmas não coincidiu com o total de localizações anatômicas, pois alguns tumores ocorreram em mais de um local. O fato de um animal apresentar mais de um tumor também foi observado por Souza et al. (2006) que verificaram que mesmo sendo muito mais freqüente o animal apresentar somente um neoplasma solitário, em aproximadamente um quinto dos casos, pode ocorrer a apresentação multicêntrica. Nessas situações, a chance dos múltiplos tumores serem do mesmo tipo é muito grande, contudo isso não permite que apenas um dos neoplasmas seja enviado para análise.

Quanto à idade, os resultados obtidos foram semelhantes aos encontrados por outros autores e indicam a tendência de cães mais velhos desenvolverem neoplasmas, com exceção do histiocitoma que é mais freqüente em cães jovens (BELLEI et. al., 2006; BRACARENSE; REIS, 1997; PIRES; TRAVASSOS; PIRES, 2003). Este fato pode ser justificado pela exposição prolongada aos agentes carcinogênicos e à diminuição da resposta imunológica em animais idosos (PRIESTER; MCKAY, 1980). A prevalência entre machos e fêmeas foi bastante similar, não havendo diferença significativa entre os sexos. Tal resultado também foi verificado por Bellei et al. (2006), entretanto, em outros estudos, quando se incluíram tumores originados no tecido mamário, a prevalência de fêmeas acometidas por neoplasmas foi maior (BRACARENSE; REIS, 1997; PIRES; TRAVASSOS; PIRES, 2003;). Essa consiste, portanto, em uma das principais razões para não se incluírem neste estudo, os tumores originários do tecido mamário.

Em relação à distribuição racial, resultados semelhantes foram encontrados por De Nardi et al. (2002) que constataram maior envolvimento, em ordem decrescente, das raças pastor alemão, poodle e boxer. No entanto, estes autores verificaram que cães SRD foram mais acometidos, ao contrário do observado neste estudo em que animais com raça definida foram mais prevalentes. Estes resultados podem, provavelmente, ser justificados pela grande quantidade de atendimentos de cães destas raças no Hospital Veterinário/UEL. Os cães da raça boxer possuem maior predisposição ao desenvolvimento de neoplasmas, particularmente acima dos oito anos de idade (COHEN et al., 1974; CULLEN; PAGE; MISDORP, 2002). Os cães da raça poodle, de acordo com a literatura, assumem grande destaque na ocorrência de neoplasmas epiteliais, apresentando uma alta prevalência de carcinomas basocelulares e tumores acometendo as glândulas sebáceas e perianais (VAIL; WITHROW, 2007).

Nove das 14 raças definidas mais acometidas são consideradas de grande porte. A razão para esta ocorrência permanece incerta. No entanto, é importante destacá-la de modo que os clínicos façam avaliações detalhadas em cães destas raças e principalmente em animais idosos. É interessante ressaltar também que a prevalência de neoplasmas apresentada pela raça fila brasileiro foi semelhante à observada em outras raças de grande porte. Como esta raça é pouco conhecida na literatura internacional, faz-se necessário destacar sua ocorrência para que estudos posteriores possam ser realizados com objetivo de determinar a existência de sua predisposição a algum tipo de neoplasia.

Quanto aos tumores mesenquimais malignos, a maioria dos sarcomas não possui predileção racial. Entretanto, os sarcomas de tecidos moles tendem a ser mais freqüentes em raças grandes (GOLDSCHMIDT; HENDRICK, 2002), podendo assim justificar a alta prevalência encontrada de cães das raças boxer e pastor alemão. Adicionalmente, observou-se entre estes, uma grande ocorrência de neoplasmas sugestivos de osteossarcomas. Esses tumores acometem freqüentemente animais de raças grandes a gigantes e cães da raça boxer e rottweiler possuem alto risco de desenvolverem tal neoplasia (COHEN et al., 1974; MACEWEN et al., 2001). 
As informações apresentadas revelaram ainda, uma alta prevalência de animais da raça boxer acometidos por mastocitomas e linfomas, de modo similar ao relatado por outros autores (MORENO; BRACARENSE, 2007; ROCHA et al., 2004). No presente estudo, do total de animais com raça definida acometidos por mastocitoma, 46,38\% eram da raça boxer. Freqüência semelhante foi relatada por De Nardi et al. (2002) que verificaram que $46,15 \%$ dos cães com mastocitoma eram desta raça.

\section{Conclusão}

A citologia é utilizada rotineiramente no Hospital Veterinário da Universidade Estadual de Londrina e demonstra ser uma técnica simples, de custo baixo e segura para o paciente. $\mathrm{O}$ exame citológico, apesar das vantagens apresentadas, não exclui o exame histopatológico, mas permite uma orientação ao clínico quanto à abordagem terapêutica.

A análise dos resultados permite inferir que os tumores de células redondas são mais freqüentes nesta população hospitalar de Londrina e que o incremento na ocorrência dos diversos neoplasmas esteja associado a maior longevidade dos animais. Além disso, raças como o fila brasileiro, pouco conhecida na literatura internacional, podem ser predispostas ao surgimento de tumores cutâneos. A avaliação contínua dos aspectos epidemiológicos associada ao diagnóstico dos neoplasmas pode contribuir para a identificação de possíveis fatores carcinogênicos e do risco de desenvolvimento dos diferentes tipos de neoplasmas.

\section{Referências}

BELLEI, M. H. M.; NEVES, D. S.; GAVA, A.; LIZ, P. P.; PILATI, C. Prevalence study of canine skin tumours in Santa Catarina, Brazil, between 1998 and 2002. Revista de Ciencias Agroveterinarias, Lages, v. 5, n. 1, p. 73-79, 2006.

BRACARENSE, A. P. F. R. L.; REIS, A. C. F. Citologia aspirativa em animais domésticos: Estudo retrospectivo. Semina: Ciências Agrárias, v. 18, n. 1, p. 27-32, 1997.
BUSSADORI, U. B. C.; DE LORENZI, A. Z. D.; BERTAZZOLO, C. M. W.; GHISLENI, S. F. G.; CAPOBIANCO, R.; CANIATTI, M. Percutaneous fine needle biopsy of deep thoracic and abdominal masses in dogs and cats. Journal of Small Animal Practice, Oxford, v. 45, n. 4, p. 191-198, 2004.

COHEN, D.; REIF, J. S.; BRODEY, R. S.; KEISER, H. Epidemiological analysis of the most prevalent sites and types of canine neoplasia observed in a veterinary hospital. Cancer Research, Baltimore, v. 34, n. 11, p. 2859-68, 1974.

CULLEN, J. M.; PAGE, R.; MISDORP, W. An overview of cancer pathogenesis, diagnosis and management. In: MEUTEN, M. D. (Ed.). Tumors in domestic animals. 4. ed. Iowa: Iowa State Press, 2002. p. 3-44.

DE NARDI, A. B.; RODASKI, S.; SOUSA, R. S.; COSTA, T. A.; MACEDO, T. R.; RODIGHERI, S. M.; RIOS, A.; PIEKARZ, C. H. Prevalence of neoplasmas and kind of treatments in dogs seen in veterinary hospital at University Federal of Paraná. Archives of Veterinary Science, Curitiba, v. 7, n. 2, p. 15-26, 2002.

DEAN, A. G. ; DEAN, J. A. ; COLOMBIER, D.; BRENDEL, K. A.; SMITH, D. C.; BURTON, A. H.; DICKER, R. C.; SULLIVAN, K.; FAGAN, R. F.; ARNER, T. G. Epi-Info, Version 6: A word processing database and statistics program for epidemiology on microcomputers. Atlanta: CDC, 1994.

DOBSON, J. M; SAMUEL, S.; MILSTEIN, H.; ROGERS, K.; WOOD, J. L. N. Canine neoplasia in the UK: Estimates of incidence rates from a population of insured dogs. Journal of Small Animal Practice, Oxford, v. 43, n. 6 , p. 240-246, 2002.

DUNCAN, J. D.; PRASSE, K. W. Cytology of canine cutaneous round cell tumors. Veterinary Pathology, Washington, v. 16, n. 6, p. 673-9, 1979.

GALlAGHER, R. P.; LEE, T. K. Adverse effects of ultraviolet radiation: a brief review. Progress in Biophysics and Molecular Biology, Oxford, v. 92, n. 1, 119-131, 2006.

GOLDSCHMIDT, M. H.; HENDRICK, M. J. Tumors of the skin and soft tissues. In: MEUTEN, M. D. (Ed.). Tumors in domestic animals. 4. ed. Iowa: Iowa State Press, 2002. p. 45-117.

GOLDSCHMIDT, M. H.; SHOFER, E. S. Skin tumors of the dog and cat. Oxford: Pergamon, 1992.

GUEDES, R. M. C.; ZICA, K. G. B.; GUEDES, M. I. M. C.; OLIVEIRA, S. R. Accuracy of cytological exam for diagnosis of inflammatory and proliferative process in domestic animals. Arquivo Brasileiro de Medicina 
Veterinária e Zootecnia, Belo Horizonte, v. 52, n. 5, p. 437-9, 2000.

HARRISON, S. L.; MACLENNAN, R.; BUETTNER, P. G. Sun exposure and the incidence of melanocytic nevi in young Australian children. Cancer Epidemiol Biomarkers and Prevention, Philadelphia, v. 17, n. 9, p. 2318-24, 2008.

KOENIG, A.;WOJCIESZYN, J.; WEEKS, B. R.; MODIANO, J. F. Expression of S100a, vimentin, NSE, and melan A/MART-1 in seven canine melanoma cell lines and twenty-nine retrospective cases of canine melanoma. Veterinary Pathology, Washington, v. 38, n. 4, p. 427-435, 2001.

LARKIN, H. A. Veterinary cytology: Fine needle aspiration of masses or swellings on animals. Irish Veterinary Journal, Dublin, v. 47, p. 65-73, 1994.

LEVER, J. V.; TROTT, P. A.; WEBB, A. J. Fine needle aspiration cytology. Journal of Clinical Pathology, London, v. 38, n. 1, p. 1-11, 1985.

MACEWEN, E. G. Miscellaneous tumors. In: WITHROW, S.J.; MACEWEN, E.G. (Ed.). Small animal clinical oncology. 3. ed. Philadelphia: W. B. Saunders Company, 2001. p. 639-646.

MACEWEN, E. G.; POWERS, B. E.; MACY, D.; WITHROW, S. J. Soft tissue sarcomas. In: Withrow, S.J.; Macewen, E.G. (Ed.). Small animal clinical oncology. 3. ed. Philadelphia: W. B. Saunders Company, 2001. p. 283304.

MAGALHÃES, A. M.; RAMADILHA, R. R.; BARROS, C. S. L.; PEIXOTO, P. V. Estudo comparativo entre citopatologia e histopatologia no diagnóstico de neoplasmas caninos. Pesquisa Veterinária Brasileira, Rio de Janeiro, v. 21, n. 1, p. 23-32, jan./mar. 2001.

MARIA, P. P.; SOBRAL, R. A.; DALECK, C. R. Casuística de cães portadores de neoplasmas atendidos no Hospital Veterinário da Unesp Jaboticabal, durante o período de 01/01/95 a 01/05/97. In: CONGRESSO BRASILEIRO DE CIRURGIA E ANESTESIOLOGIA VETERINÁRIA, 3., 1998, Belo Horizonte. Anais... Santa Maria: Colégio Brasileiro de Cirurgia e Anestesiologia Veterinária, 1998. p. 61.

MÉNARD M.; FONTAINE, M.; MORIN, M. Fine needle aspiration biopsy of malignant tumors in dogs and cats: A report of 102 cases. Canadian Veterinary Journal, Ottawa, v. 27, n. 12, p. 504-10, 1986.

MILLS, J. N.; GRIFFITHS, G. L. The accuracy of clinical diagnosis by fine needle aspiration cytology. Australian Veterinary Journal, Brunswick, v. 61, n. 8, p. 269-71, 1984.
MORENO, K.; BRACARENSE, A. P. F. R. L. Estudo retrospectivo de linfoma canino no periodo de 1990-2004 na região norte do Paraná. Brazilian Journal of Veterinary Research and Animal Science, São Paulo, v. 44, Supl., p. 46-52, 2007.

MORRISON, W. B.; DE NICOLA, D. B. Advantages and disadvantages of cytology and histopathology for the diagnosis of cancer. Seminars in Veterinary Medicine and Surgery: Small Animal, Philadelphia, v. 8, n. 4, p. 222-227, 1993.

ORTEGA-PACHECO, A.; SEGURA-CORREA, J. C.; JIMENEZ-COELHO, M.; LINDE FORSBERG, J. Reproductive patterns and reproductive pathologies of stray bitches in the tropics. Theriogenology, Stoneham, v. 67, n. 2, p. 382-90, 2007.

PEHARDA, V.; GRUBER, F.; KASTELAN, M.; MASSARI, L. P.; SAFTIC, M.; CABRIJAN, L.; ZAMOLO, G. Occupational skin diseases caused by solar radiation. Collegium Antropologicum, Zagreb, Suppll. 1, p. 87-90, 2007.

PIRES, M. A.; TRAVASSOS, F. S.; PIRES, I. Dog's neoplasia - A six years descriptive study. Revista Portuguesa de Ciências Veterinárias, Lisboa, v. 98, n. 547, p. 111-118, 2003.

PRIESTER, W. A.; MCKAY, F. W. The occurrence of tumors in domestic animals. Journal of the National Cancer Institute Monographs, Bethesda, n. 54, p. 210216, Nov. 1980.

RASKIN, R. E. Classificação geral das alterações citológicas. In: RASKIN, R. E.; MEYER, D. J. Atlas de citologia de cães e gatos. São Paulo: Roca, 2003. p. 1727.

REPPAS, G.; CANFIELD, P. Citologia diagnóstica de lesiones cutâneas em el perro y em el gato. Parte 2: Evaluación citológica de las lesiones cutáneas. Veterinary International, Barcelona, v. 7, n. 1, p. 17-29, 1995.

ROCHA, T. M.; FARIAS, M. R.; WOUK, A. F. P. F.; CIRIO, S. M.; MIARA, L. C. Mast cell tumor in dogs review. Clínica Veterinária, São Paulo, n. 52, p. 56-64, 2004.

SITUM, M.; BULJAN, M.; BULIC, S. O.; SIMIC, D. The mechanisms of UV radiation in the development of malignant melanoma. Collegium Antropologicum, Zagreb, Suppll. 1, p. 13-16, 2007.

SOUZA, T. M.; FIGHERA, R. A.; IRIGOYEN, L. F.; BARROS, C. S. L. Retrospective study on 761 canine skin tumors. Ciência Rural, Santa Maria, v. 36, n. 2, p. 555-60, 2006. 
THAMM, D. H.; VAIL, D. M. Mast cell tumors. In: WITHROW, S. J.; MACEWEN, E. G. (Ed.). Small animal clinical oncology. 3. ed. Philadelphia: W. B. Saunders Company, 2001. p. 261-82.

TYLER, R. D.; COWELL, R. L.; BALDWIN, C. J.; MORTON, R. J. Introduction. In: COWELL, R. L.; TYLER, R. D.; MEINKOTH, J. H. Diagnostic cytology and hematology of the dog and cat. 2. ed. Saint Louis: Mosby, 1999. p. 1-20.

VAIL, D. M.; MACEWEN, E. G.; YOUNG, K. M. Canine lymphoma and lymphoid leukemias. In: WITHROW, S. J.; MACEWEN, E. G. Small animal clinical oncology. 3. ed. Philadelphia: W. B. Saunders Company, 2001. p. 558-590.
VAIL, D. M.; WITHROW, S. J. Tumors of the skin and subcutaneous tissues. In: WITHROW, S. J.; MACEWEN, E. G. Small animal clinical oncology. 4. ed. Philadelphia: W. B. Saunders Company, 2007. p. 375-401.

WELLMAN, M. L. Cytology and the diagnosis of neoplasia. In: ANNUAL WALTHAM SYMPOSIUM FOR THE TREATMENT OF SMALL ANIMAL DISEASES (ONCOLOGY AND HEMATOLOGY), 20., 1996, Vernon. Anais... Vernon: Waltham, 1996. p. 11-20.

WITHROW, S. J. Why worry about cancer in pets? In: WITHROW, S. J.; MACEWEN, E. G. (Ed.). Small animal clinical oncology. 4. ed. Philadelphia: W. B. Saunders Company, 2007. p. 15-17. 